radiographs are commonly inadequate for diagnosing conditions such as spondylitis, metastasis at the base of a pedicle, and listhesis, ${ }^{18}$ and therefore, apparently normal routine radiographs should not be considered adequate if the clinical picture indicates important disease.

It is surprising that so few patients were fully examined and that so many were not examined before the radiographs were requested. Although patients may forget much of what their general practitioner tells them in a consultation, we consider that most will remember whether or not they have been examined. At this unit most patients will have had their examination performed within a few days of the request so that elapsed time does not become a major factor in accuracy of recall. We thus believe that our figures are a reasonable approximation to the truth. It can only be that most of the doctors in our sample currently make their decision to request radiographs based on the patient's history and that the examination findings are unlikely to alter this decision one way or the other. We hope that dissemination of the college guidelines will help to modify this decision making process.

Few of the general practitioners we contacted were aware of the college guidelines, and most expressed an interest in seeing them. Radiologists should strive to ensure that their local general practitioners are informed of the guidelines and should discuss their implications with them.

Despite the pessimism of some authors, ${ }^{19}$ there is evidence that educating clinicians about radiology can reduce the number of unnecessary examinations, ${ }^{2021}$ and in view of the many patients referred to our department for lumbar spine radiography, we hope that widespread acceptance of the guidelines will result in optimal use of radiological services. We also believe that there is a need for a guided increase in public awareness regarding the radiation engendered in diagnostic radiology. Though we do not wish to cause unnecessary concern, the community as a whole would benefit from a reduction in medical radiation that might follow reduced demand from patients to have radiographic examinations for painful but benign conditions.

1 National Radiological Protection Board. Radiation exposure of the UK population-1988 Review. London: HMSO, 1989. (NRPB-R227.)

2 National Radiological Protection Board. Living with radiation. London HMSO, 1989

3 National Radiological Protection Board. A national survey of doses to patients undergoing a selection of routine $x$ ray examinations in English hospitals. London: HMSO, 1986. (NRPB-R200)

4 The Royal College of Radiologists. Making the best use of a department of radiologv: guidelines for doctors. London: Royal College of Radiologists, 1989. radiologv: guidelines for doctors. London: Royal College of Rad5.

6 International Commission on Radiation Protection. Statement from the 1987 meeting of the ICRP. National Radiological Protection Board Radiological meeting of the ICRP. National Rad

7 National Radiological Protection Board. Patient dose reduction in diagnostic radiology. London: HMSO, 1990.

8 Roberts CJ. Costs and benefits of skull radiography for head injury. A national study by the Royal College of Radiologists. Lancet 1981;ii:791-5.

9 Roberts CJ. The effective use of diagnostic radiology. $\mathcal{F} R$ Coll Physicians Lond 1984;18:62-5.

10 Roberts CJ. Annotation: towards the more effective use of diagnostic radiology: a review of the Royal College of Radiologists working party on the more effective use of diagnostic radiology, 1976 to 1986. Clin Radiol 1988;39:3-6.

11 Pearson R. Radiography in women of childbearing age. BMf 1989;299: 1175-6.

12 Edelstyn GA, Gillespie PT, Crebbel FS. Radiological demonstration of osseous metastases: experimental observations. Clin Radiol 1967;18:158-62.

13 Quintet RJ, Hadler NM. Diagnosis and treatment of back pain. Semi Arthritis Rheum 1979;8:261-87.

14 Waddell G. An approach to backache. Br f Hosp Med 1982;28:187-219.

15 Kelen GD, Noii EK, Doris PE. Guidelines for the use of lumbar spine radiography. Ann Emerg Med 1986;15:245-51.

6 Nachemson A. A critical look at conservative treatment for low back pain. In Jayson M, ed. The lumbar spine and back pain. London: Sector, 1976:355-66.

17 South East Thames Regional Health Authority. Making the best of an imagin department: guidelines for doctors. London: SETRHA, 1990.

18 Butt WP. Radiology for back pain. Clin Radiol 1989;40:6-10.

19 Ryan M, Mooney G. Research on medical practice variation: Where now? Aberdeen: HERU, University of Aberdeen, 1991. (Available from HERU.)

20 Fowkes FGR, Evans RC, Williams LA, Gelbach SH, Cooke BRB, Roberts CJ. Implementation of guidelines for the use of skull radiographs in patients with head injuries. Lancet 1984;ii:795-6.

21 Fowkes FGR, Davies ER, Evans, KT, Green G, Hugh AE, Nolan DJ. Compliance with the Royal College of Radiologists guidelines on the use of preoperative chest radiographs. Clin Radiol 1987;38:45-8.

(Accepted 29 August 1991)

\title{
Association between secretor status and respiratory viral illness
}

\author{
M W Raza, C C Blackwell, P Molyneaux, V S James, M M Ogilvie, J M Inglis, D M Weir
}

Department of Medical Microbiology, University of Edinburgh Medical School, Edinburgh EH8 9AG

M W Raza, MB, postgraduate student

C C Blackwell, PHD, senior lecturer

V S James, FIMLs, research technician

M M Ogilvie, MD, senior lecturer

D M Weir, FRCPED, professor

Regional Virus Laboratory, City Hospital, Edinburgh P Molyneaux, MB, senior registrar

$\mathrm{J}$ M Inglis, PHD, director

Correspondence to:

Dr Blackwell.

BMF 1991;303:815-8

\section{Abstract}

Objective-To determine whether non-secretion of blood group antigens is associated with respiratory virus diseases.

Design-Study of secretor status in patients with respiratory virus diseases determined by an enzyme linked immunosorbent assay (ELISA) developed to identify Lewis (Le) blood group antigen phenotypes (Le ${ }^{a}$ non-secretor; Le ${ }^{b}$ secretor).

Subjects-Patients aged 1 month to 90 years in hospital with respiratory virus diseases (584 nasal specimens).

Main outcome measures-Criteria for validation of ELISA (congruence between results on ELISA testing of 1155 saliva samples from a previous study and previously established results on haemagglutination inhibition (HAI) testing, proportions of $\mathrm{Le}^{\mathrm{a}}$, $\mathrm{Le}^{\mathrm{b}}$, and $\mathrm{Le}^{-}$phenotypes in 872 samples of nasal washings from a previous study compared with the normal population). Secretor status of patients determined by ELISA and viruses isolated.

Results-Agreement between HAI and ELISA for 1155 saliva samples was $97 \%$. Lewis antigens were detected by ELISA in $854(97.9 \%)$ of nasal washings $\left(\mathrm{Le}^{\mathrm{a}} 233(26 \cdot 7 \%), \mathrm{Le}^{\mathrm{b}} 621(71 \cdot 2 \%)\right.$, and $\mathrm{Le}^{-} 18$ $(2 \cdot 1 \%))$ in proportions predicted for a northern European population. Secretors were significantly overrepresented among patients from whom influenza viruses $A$ and $B(55 / 64,86 \% ; p<0.025)$, rhinoviruses $(63 / 72,88 \% ; p<0.01)$, respiratory syncytial virus $(97 / 109,89 \% ; p<0.0005)$, and echoviruses $(44 / 44, p<0.0005)$ had been isolated compared with the distribution of secretors in the local population.

Conclusion-Secretion of blood group antigens is associated with respiratory virus diseases.

\section{Introduction}

Susceptibility to a variety of bacterial and superficial fungal infections is associated with the genetically controlled inability of individual subjects to secrete the water soluble form of the $\mathrm{ABO}$ blood group antigens into body fluids (non-secretion). ${ }^{1-7}$ Non-secretors are also significantly overrepresented among patients with some autoimmune diseases for which infectious triggers have been proposed. ${ }^{8-12}$ Although studies of associations between ABO blood groups and susceptibility to natural or experimental viral infections have been reported, ${ }^{13-15}$ there are no published studies of secretor status and viral infection. In this study we tested the hypothesis that non-secretors might also be at increased risk of viral illnesses.

Because the quantities of material available from 
patients with viral diseases were too small to determine secretor status by the usual haemagglutination inhibition method, ${ }^{16}$ we developed an enzyme linked immunosorbent assay (ELISA) to detect Lewis blood group antigens in the specimens. Non-secretors express only Lewis ${ }^{\mathrm{a}}\left(\mathrm{Le}^{\mathrm{a}}\right)$ antigen and secretors express Lewis $^{\mathrm{b}}\left(\mathrm{Le}^{\mathrm{b}}\right)$ antigen on their red blood cells and in their body fluids.

\section{Materials and methods} ELISA FOR LEWIS ANTIGENS

To detect the presence of $\mathrm{Le}^{\mathrm{a}}$ and $\mathrm{Le}^{\mathrm{b}}$ blood group antigens in body fluids by ELISA wells of polystyrene microtitre plates (Dynatech, Billingshurst, Sussex) were coated overnight at $4^{\circ} \mathrm{C}$ with $100 \mu \mathrm{l}$ of monoclonal $\mathrm{Le}^{\mathrm{a}}$ antibody (LM 112/161) or $100 \mu \mathrm{l} \mathrm{Le}{ }^{\mathrm{b}}$ antibody (LM 129/81 anti-Le ${ }^{\mathrm{bL}}$ ) (provided by $\mathrm{R} \mathrm{H}$ Fraser, Glasgow and West Scotland Blood Transfusion Service). $\mathrm{Le}^{\mathrm{a}}$ antibody was diluted 1 in 25 and $\mathrm{Le}^{\mathrm{b}}$ diluted 1 in 20 in $50 \mathrm{mM}$ sodium carbonate buffer ( $\mathrm{pH} \mathrm{9.6).} \mathrm{All} \mathrm{further} \mathrm{procedures} \mathrm{were} \mathrm{carried} \mathrm{out} \mathrm{at}$ room temperature except when stated otherwise. The wells were washed three times with $0 \cdot 1 \mathrm{M}$ phosphate buffered saline containing $0 \cdot 1 \%$ (wt/vol) bovine serum albumin and $0.05 \%(\mathrm{vol} / \mathrm{vol}$ ) Tween 20 (washing buffer). The wells were blocked with $150 \mu$ l of phosphate buffered saline with $1 \%(\mathrm{wt} / \mathrm{vol})$ bovine serum albumin (blocking buffer) for 15 minutes. The buffer was removed and the wells washed twice with washing buffer.

Dilutions of saliva from known secretors or nonsecretors were used in each plate as controls. Test wells contained $100 \mu \mathrm{l}$ of the specimen (saliva, nasal washings, or respiratory secretions) which had been boiled for 30 minutes to inactivate enzymes, bacteria, or viruses. Samples of saliva were diluted 1 in 20 in blocking buffer for detecting $\mathrm{Le}^{\mathrm{b}}$ antigen and 1 in 100 for detecting $\mathrm{Le}^{\mathrm{a}}$ antigen. The more dilute nasal washings or respiratory specimens were diluted 1 in 10 in blocking buffer to detect $\mathrm{Le}^{\mathrm{a}}$ antigen but were used undiluted to detect $\mathrm{Le}^{\mathrm{b}}$ antigen.

After incubation for one hour the wells were washed three times and $100 \mu \mathrm{l}$ of polyclonal goat anti-Le $\mathrm{Le}^{\mathrm{a}}$ antibody (Behring, Marburg, West Germany) diluted 1 in 500 in blocking buffer or $100 \mu \mathrm{l}$ of polyclonal goat anti-Le ${ }^{\mathrm{b}}$ antibody (Behring) diluted 1 in 250 in blocking buffer were added to the wells of the appropriate plates. After 30 minutes' incubation the plates were washed three times, and $100 \mu \mathrm{l}$ of horseradish peroxidase conjugated donkey antigoat immunoglobulin (Scottish Antibody Production Unit, Carluke, Lanarkshire) diluted 1 in 250 in blocking buffer was added. After overnight incubation at $4^{\circ} \mathrm{C}$ the plates were washed three times and $100 \mu \mathrm{l}$ of orthophenylene diamine $(40 \mathrm{mg}$ in $100 \mathrm{ml} 0.1 \mathrm{M}$ phosphate citrate buffer, $\mathrm{pH}$ 5) activated with $40 \mu \mathrm{l}$ hydrogen peroxide $(30 \%)$ were added to each well. The colour was allowed to develop for 10-15 minutes, and the reaction was stopped by adding $50 \mu \mathrm{l}$ of $12 \cdot 5 \%$ sulphuric acid to each well.

Absorbance at $490 \mathrm{~nm}$ was measured with a plate reader (Dynatech). Samples were tested in duplicate, and the readings were averaged. The average reading for each sample was compared with the results obtained for dilutions of saliva from secretors (diluted 1 in 20) and non-secretors (diluted 1 in 100) in the same plate. Values equal to or above that of the control were considered to be positive. The subjects from whom the samples were obtained were classified as non-secretors if only $\mathrm{Le}^{\mathrm{a}}$ antigen was detected or as secretors if $\mathrm{Le}^{\mathrm{b}}$ antigen or $\mathrm{Le}^{\mathrm{a}}$ and $\mathrm{Le}^{\mathrm{b}}$ antigens were detected.

\section{SAMPLES AND CONTROLS}

To assess the method we compared the results obtained by the ELISA with those obtained by a haemagglutination inhibition assay ${ }^{16}$ for 1155 saliva specimens collected during the Stonehouse survey. ${ }^{17}$ Nasal secretions were collected from 26 members of staff whose secretor status and Lewis blood group antigens had been previously determined. The secretions were collected with cotton wool swabs, inoculated into virus transport medium, and the transport medium processed and assayed for presence of Lewis antigens. Nasal washings $(n=872)$ obtained as part of other studies at the Medical Research Council's Common Cold Unit were also tested to determine if Lewis antigens could be detected in diluted nasal secretions. They had originally been obtained from volunteers for assessment of secretory antibodies and had been stored at $-20^{\circ} \mathrm{C}$ for four to five years.

As there is no association between sex and secretor status or sex and the Lewis blood group ${ }^{18}$ the distribution of $\mathrm{Le}^{\mathrm{a}}$ and $\mathrm{Le}^{\mathrm{b}}$ antigens in the local population was determined with red blood cells from 363 women attending antenatal clinics at the Royal Infirmary, Edinburgh, by the standard tube agglutination method with the monoclonal $\mathrm{Le}^{\mathrm{a}}$ and $\mathrm{Le}^{\mathrm{b}}$ antibodies referred to above in $10 \%$ dextran and $2 \%$ bovine serum albumin. The results were compared with those of a previous study of the local population in which secretor status of 334 blood donors was determined from saliva by haemagglutination inhibition. ${ }^{3}$ Specimens sent to the regional virus laboratory for examination $(n=584)$, mainly from patients aged from 1 month to 90 years in hospital with symptoms of viral disease, were used in this study. These were aspirated respiratory secretions or nasal or throat swabs inoculated into virus transport medium which had been stored at $-70^{\circ} \mathrm{C}$ after culture for virus (table I). The results for the local population and test specimens were compared by the $\chi^{2}$ test incorporating Yates's correction factor. Odds ratios and $95 \%$ confidence intervals were calculated by the exact method.

TABLE I-Source of specimens for determination of Lewis blood group and secretor status

\begin{tabular}{llr}
\hline Source & Specimen & No \\
\hline Controls: & & \\
$\quad$ Local antenatal clinic & Blood & 363 \\
Local antenatal clinic $^{3}$ & Saliva & 334 \\
Stonehouse survey & Blood and saliva & 1155 \\
MRC Common Cold Unit & Nasal washings & 872 \\
Laboratory staff & Saliva, blood, and nasal swabs & 26 \\
& inoculated into virus \\
& transport medium & \\
Patients: & Nasal secretions & \\
Regional virus laboratory & OR & \\
& Swabs inoculated into virus & \\
& transport medium & \\
\hline
\end{tabular}

\section{Results}

ASSESSMENT OF ELISA FOR DETECTING LEWIS ANTIGENS IN BODY FLUIDS

$\mathrm{Le}^{\mathrm{a}}$ or $\mathrm{Le}^{\mathrm{b}}$ antigens or both, were detected by ELISA in 1089 of the 1155 (94.3\%) specimens of saliva for which secretor status had been determined by haemagglutination inhibition. The results of ELISA for Lewis antigens and of the haemagglutination inhibition assay agreed for 1058 of the 1089 Lewis positive specimens $(97 \%), 796 \mathrm{Le}^{\mathrm{b}}$ antigen positive (secretors) and $262 \mathrm{Le}^{\mathrm{a}}$ antigen positive (non-secretors). The results for the two assays disagreed for 31 specimens, $27 \mathrm{Le}^{\mathrm{a}}$ antigen positive (but secretors by haemagglutination inhibition) and four $\mathrm{Le}^{\mathrm{b}}$ antigen positive (but non-secretors by haemagglutination inhibition). In 66 specimens $(5 \cdot 7 \%)$ Lewis antigens were not detected by ELISA: 30 were from secretors and 36 from non-secretors. Lewis phenotype determined by agglutination of red blood cells for 124 of these donors 
agreed with the results of the ELISA for 119 (96\%) of those tested. The ELISA correctly identified the Lewis antigen present in nasal secretions of all 26 laboratory staff. Among the 872 nasal washings obtained from the Common Cold Unit, Lewis antigens were detected in $854(97.9 \%): \mathrm{Le}^{\mathrm{a}}$ antigen in $233(26.7 \%)$ Le $^{\mathrm{b}}$ antigen in $621(71 \cdot 2 \%)$; and no Lewis antigen in $18(2 \cdot 1 \%)$. This finding does not differ from the distribution of those phenotypes in most northern European populations. ${ }^{18}$

\section{LEWIS PHENOTYPES OF LOCAL POPULATION}

Among 363 blood specimens from the antenatal clinic in which the Lewis antigens were detected, $28 \%$ were $\mathrm{Le}^{\mathrm{a}}$ antigen positive only and $72 \%$ were $\mathrm{Le}^{\mathrm{b}}$ antigen positive (tabe II). These results were not significantly different from the proportions of nonsecretors $(26.6 \%)$ and secretors $(73 \cdot 4 \%)$ determined in a previous study by haemagglutination inhibition tests of 334 samples of saliva from local blood donors. ${ }^{3}$

\section{LEWIS PHENOTYPE OF PATIENTS WITH VIRAL} ILLNESSES

In 192 of the 584 (33\%) patients' specimens examined by ELISA not enough Lewis antigen was detected for definite classification: 81 showed borderline readings, and in 111 no antigen was detectable. The results obtained with these specimens most probably reflect degradation of the antigens due to delays in their transportation to the laboratory. No virus was isolated from $38(20 \%)$ of these 192 specimens. Among the 392 specimens in which either or both Lewis antigens were definitely detected, no virus was isolated from $36(9 \%)\left(\chi^{2}=12 \cdot 17, \mathrm{p}<0 \cdot 0005\right)$. The proportion of unclassifiable specimens did not vary significantly with respect to isolation of any particular virus. As the specimens giving negative and borderline results for Lewis antigens could not be classified as being from secretors or non-secretors they were eliminated from further analysis.

TABLE II - Lewis phenotype and secretor status of patients and controls and results of virus culture



^Odds ratio compared with local controls.

Table II compares the isolation of viruses from nonsecretors and secretors. Compared with the local population, there was a significantly higher proportion of secretors among subjects from whom the following viruses were isolated: influenza $A$ virus $(p<0.05)$, rhinovirus $(p<0.01)$, respiratory syncytial virus $(p<0.0005)$, and echoviruses $(p<0 \cdot 0005)$. Although 11 of 13 specimens containing influenza $B$ virus were from secretors, the numbers were too small to be significant. This pattern was not observed for the 67 specimens from which parainfluenza virus was isolated or the 36 from which no virus was isolated. In these two groups of specimens the proportions that were $\mathrm{Le}^{\mathrm{b}}$ antigen positive (secretors) and $\mathrm{Le}^{\mathrm{a}}$ antigen positive (non-secretors) were similar to those of the local population.

\section{Discussion}

Determination of Lewis phenotype is a good control for haemagglutination inhibition assays for ABO antigens which have been the standard method for determining secretor status. Agreement between the Lewis phenotypes and results of the haemagglutination inhibition assay for 1089 saliva specimens was 97\%. "False secretors," of Le $\mathrm{Le}^{\mathrm{a}}$ phenotype but secretors by haemagglutination inhibition, were the predominant mismatched pairs $(27 / 31,87 \%)$. Results of a previous study indicate that these are most likely the result of contamination of saliva by blood owing to poor oral hygiene or periodontal disease among these subjects. ${ }^{17}$ Dilution of small samples to provide enough material for the haemagglutination inhibition test is probably the source of the small proportion $(0.004 \%)$ of "false non-secretors," who are of Le ${ }^{b}$ phenotype but non-secretors by haemagglutination inhibition. The ELISA method eliminates the problem of contamination of non-secretor saliva by red blood cells and it can be carried out on smaller volumes than those needed for haemagglutination inhibition. The method also detected Lewis antigens in $854(98 \%)$ of the 872 specimens from the Common Cold Unit, indicating that the method can be used to detect these antigens in diluted nasal secretions.

The nasal washings from volunteers at the Common Cold Unit were originally collected for determining secretory antibody titres and were frozen soon after collection, which would preserve the Lewis antigens; analysis of the results found the expected proportion (2\%) of specimens negative for Lewis antigen. The high proportion of specimens from patients in hospital with viral illness for which borderline readings were obtained or in which no Lewis antigen was detected might be due, in part, to collection techniques and time taken for transportation and processing the specimens. Blood group antigens cannot be reliably detected in saliva kept overnight at room temperature. There was a significantly higher proportion of unclassifiable specimens from which no virus was isolated $(20 \%)$ compared with the proportion of specimens in which Lewis antigens were definitely detected but from which no virus was isolated $(9 \%)(\mathrm{p}<0.0005)$. The proportion of unclassifiable specimens was not greater among the very young age groups ( $<24$ months), from whom nasopharyngeal secretions are usually obtained. Although the Lewis antigens were correctly identified in all the samples of transport medium inoculated with nasal swabs obtained from 26 laboratory staff, secretions provide a larger quantity of material for isolating virus and detecting Lewis antigen.

Previous studies found non-secretion to be associated with various bacterial diseases and superficial yeast infections and with carriage of some pathogenic bacteria or yeasts. ${ }^{19-21}$ These findings contrast with our present finding in which secretors were overrepresented among those patients with significant symptoms of respiratory illness and from whom influenza A virus, rhinovirus, or respiratory syncytial virus were isolated. Secretors were also significantly overrepresented among those from whom echoviruses were isolated; these patients, however, had various illnesses including meningitis, fever, and vomiting. An increase in the proportion of secretors was not associated with isolation of parainfluenza virus or with the group of individual subjects from whom no virus was isolated.

This is the first report of associations between secretion of blood group antigens and infectious diseases. There is evidence that the $\mathrm{Le}^{\mathrm{a}}$ antigen present in greater amounts on epithelial surfaces of nonsecretors might be one of the receptors for Candida species, ${ }^{22}$ and studies in progress indicate that this might be true for Neisseria meningitidis. The hypothesis 
that antigens present only in secretors $\left(\mathrm{Le}^{\mathrm{b}}\right)$ or in higher quantities in secretors $(\mathrm{H}$ type $\mathrm{l}$ in addition to $\mathrm{H}$ type 2$)^{23}$ might act as one of the receptors for some viruses is under investigation.

This work is supported by grants from the Scottish Cot Death Trust, TENOVUS-Scotland, and the North East Scotland Meningitis Appeal. We thank Dr R H Fraser and Dr G Inglis from the Glasgow and West of Scotland Blood Transfusion Service for helpful discussions and for the monoclonal antibodies used in this study, Dr D A J Tyrell and Mrs C Brown of the MRC Common Cold Unit for supplying specimens of nasal washings, Dr R A Elton for statistical advice, and Mrs M K Cole for preparing the manuscript. MWR has a grant from the Overseas Research Student Awards Scheme.

1 Haverkorn MJ, Goslings WRO. Streptococci, ABO blood groups and secretor status. Am f Hum Genet 1969;21:360-75

2 Chaudhuri A, Das Adhikary CR. Possible role of blood-group secretory substances in the aetiology of cholera. Trans $R$ Soc Trop Med Hyg 1978;72:664-5.

3 Kinane DF, Blackwell CC, Brettle RP, Weir DM, Winstanley FP, Elton RA. $\mathrm{ABO}$ blood group, secretor state, and susceptibility to recurrent urinary ABO blood group, secretor state,

4 Blackwell CC, Jónsdótir $K$, Hanson M, Todd WTA, Chaudhuri AKR, Mathew B, et al. Non-secretion of ABO blood group antigens predisposing Mathew $\mathrm{B}$, et al. Non-secretion of $\mathrm{ABO}$ blood group antigens predisposing
to infection by Neisseria meningitidis and Streptococcus pneumoniae. to infection by $\mathrm{Ne}$.

5 Blackwell CC, Jónsdóttir K, Hanson MF, Weir DM. Non-secretion of ABO antigens predisposing to infection by Haemophilus influenzae. Lancet 1986;ii:687.

6 Blackwell CC, May SJ, Brettle RP, MacCallum CJ, Weir DM. Secretor state and immunoglobulin levels among women with recurrent urinary tract infections. F Clin Lab Immunol 1987;22:133-7.

7 Thom SM, Blackwell CC, MacCallum CJ, Weir DM, Kinane DF, Wray D. Non-secretion of $\mathrm{ABO}$ blood group antigens and susceptibility to infection by Candida species. FE.MS Microbiol Immunol 1989;7:401-6.
8 Andersen J, Laurizen E. Blood groups and diabetes mellitus, Diabees 1960;9:20-4

Blackwell CC, James VS, Weir DM, (iemmell JD, Patrick AW, Collier A et al. Secretor status of patients with insulin dependent or non-insulin dependent diabetes mellitus. BMF 1987;295:1024-5.

10 Collier A, Patrick AW, Toft AD, Blackwell CC, James VS, Weir DM Increased prevalence of non-secretors in patients with Graves' disease: evidence for an infective aetiology. $B M 7$ 1988;296:1162.

11 Shinebaum R, Blackwell CC, Forster PJG, Hurst NP, Weir DM, Nuki G. Non-secretion of $\mathrm{ABO}$ blood group antigens as host susceptibility factor in the spondylarthropathies. BMF 1987;294:208-10.

12 Blackwell CC. Genetic susceptibility to infectious agents. Proceedings of the Roval College of Phvsicians of Edinburgh 1989:19:129-35.

13 Mackenzie JS, Fimmell PJ. The effect of ABO blood groups on the incidence of epidemic influenza and on the response to live attenuated and detergent of epidemic influenza and on the response to live attenuated
split influenza vaccines. Fournal of Hygiene 1978;80:21-30.

14 MCDonald JC, Zuckerman AJ. ABO blood groups and acute respiratorv virus disease. BMF 1962;ii:89-90.

15 Potter CW. Haemagglutination inhibition antibody to various influenza viruses and adenoviruses in individuals of blood groups $\mathrm{A}$ and $\mathrm{O}$. Fournal of Hygiene 1969;67:67-74.

16 Mollison PL. Blood transfusion in clinical medicine. 6th ed. Oxford: Blackwell, 1979:414-82

17 Blackwell CC, Weir DM, James VS, Cartwright KAV, Stuart JM, Jones DM The Stonehouse study: secretor status and carriage of Neisseria meningitidis and Neisseria lactamica. Epidemiol Infect 1989;102:1-10.

18 Mourant AE, Kopeć AC, Domaniewska-Sobczak K. The distribution of the human blood groups and other polymorphisms. London: Oxford University Press, 1976.

19 Burford-Mason AP, Welsby JCP, Willoughby JMT. Oral carriage of Candida albicans, $\mathrm{ABO}$ blood group and secretor status in healthy individuals. J.Met Vet Mycol 1988:26:49-56.

20 Blackwell CC, Aly FZM, James VS, W'eir DM, Collier A, Patrick AW, et al. Blood group, secretor status and oral carriage of yeasts among patients with diabetes mellitus. Diabet Res 1989;12:101-4.

21 Blackwell CC, Weir DM, James VS, Todd WTA, Banatvala N, Chaudhur AKR, et al. Secretor status, smoking and carriage of Neisseria meningitidis. Epidemiol Infect 1990;104:203-9.

22 May SJ, Blackwell CC. W'eir DM. Lewis blood group antigen, a receptor for Candida species. FEMS Microbiol Immunol 1989;47:407-10.

23 Rahat A, Stewart J, Blackwell CC, Weir DM. Semi-quantative determination of $\mathrm{H}$ type 1 and type 2 antigens on buccal epithelial cells and in saliva of secretors and non-secretors. Vox Sang 1990;57:101-5.

(Accepted 17 July 1991

\title{
Mode of delivery after one caesarean section: audit of current practice in a health region
}

\author{
Catherine M Paterson, Nigel J St G Saunders
}

Abstract

Objective-To audit the subsequent obstetric management of women who had had one previous baby delivered by caesarean section.

Design-Retrospective analysis of a regional obstetric database.

Setting-Data derived from the 17 obstetric units in North West Thames region.

Subjects - 1059 women who delivered a singleton fetus of at least 37 weeks' gestation with a cephalic presentation in 1988 who had a history of one previous caesarean section and no other deliveries.

Main outcome measures-Mode of delivery, postnatal morbidity, and duration of hospital stay.

Results-395 (37\%) women were delivered by elective repeat caesarean section and $664(63 \%)$ were allowed a trial of labour. Maternal height and birth weight of the previous infant differed significantly between those who were and those who were not allowed to labour. $471(71 \%)$ of those allowed to labour achieved a vaginal delivery. In individual units there was no significant correlation between the proportion of patients allowed to labour and the rate of the successful trial of labour. There was a trend towards greater success rates in units that allowed a longer duration of labour $(p<0.05)$ and units with greater use of oxytocin for augmentation of labour (not significant). Both elective and intrapartum caesarean section was associated with a significantly higher rate of postnatal infection than vaginal delivery $(14.7 \%$ and $16.0 \% v 3.4 \%)$.

Conclusions-In patients with a history of caesarean section there is no evidence that the likelihood of successful vaginal delivery after trial of labour is modified by the proportion of such patients allowed the option of attempted vaginal delivery. Until selection criteria of adequate prognostic value can be identified a more liberal approach to allowing women a trial of labour seems justified.

\section{Introduction}

The rising incidence of caesarean birth in Britain and elsewhere is a cause for concern both in terms of the associated increase in clinical and social morbidity for the mother and increased cost to the health service. Repeat caesarean section makes a major contribution to the overall rate of caesarean section. One strategy for reducing the rate of caesarean birth, therefore, is to allow women with a history of lower segment caesarean section the option of a trial of labour in their next pregnancy unless there are specific contraindications.

Many studies attest to the safety of a properly conducted trial of labour in women who have previously delivered by caesarean section, and successful vaginal delivery can be expected in around two thirds of such cases. In a comprehensive review Lavin et al concluded that a properly managed trial was associated with an acceptably low incidence of scar dehiscence and perinatal mortality.' Furthermore, no maternal deaths were identified. This is in contrast to the recognised contribution of repeat elective caesarean section to maternal mortality. ${ }^{2}$

Factors known to influence the outcome of a trial of
Correspondence to:

Dr Paterson.

BMf 1991;303:818-21 